\title{
DUAS ATUALIZAÇÕES DO DISCURSO DO VELHO DO RESTELO
}

Maria Márcia Matos Pinto

Universidade de São Paulo

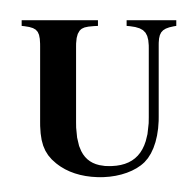

$\mathrm{m}$ dos pontos culminantes, e provavelmente o mais intrigante, da epopéia de Camões é sem dúvida alguma o discurso do Velho do Restelo por se constituir num momento de dissonância no canto de louvor épico ao grande feito de Vasco da Gama. Como discurso que se opõe à grandiosidade da empresa portuguesa, as estrofes dedicadas à fala do "velho de aspeito venerando" já provocaram uma ampla discussão crítica em torno dos motivos que levaram o autor a introduzir esta voz que distoa do conjunto de engrandecimento do feito realizado pelos "barões assinalados".

Apesar de críticos como Afrânio Peixoto terem creditado a inserção desse episódio a um mero artifício literário, ${ }^{1}$ as estrofes dedicadas à fala do velho estão em consonância com as discussões políticas da época. Salvatore D'Onofrio coloca que não havia um completo consenso entre os membros das classes então no poder sobre a relevância do projeto das navegações, ${ }^{2}$ sendo o conteúdo das estrofes talvez uma forma de dar lugar às vozes contrárias à empresa das descobertas.

De qualquer forma, é difícil ver apenas um artifício literário, desprovido de intenções ideológicas, em versos de tanta força. Por um lado eles saem da boca de alguém que tem idade e experiência, sendo capaz de enxergar mais longe do que os homens de menos

\footnotetext{
${ }^{1}$ Citado por D'ONOFRIO, 1970. p.84.

${ }^{2}$ D'ONOFRIO, 1970. p.80.
} 
idade, entusiasmados com as riquezas do Oriente. Por outro, os versos não são uma mera projeção do futuro, mas a constatação de um processo de decadência econômica que era visível ao tempo de Camões. Como nos diz António Sérgio:

Toda a riqueza do Oriente passava apenas por Portugal, e ia fomentar o trabalho estrangeiro, que nos fornecia de todas as coisas... Entretanto, morria-se de fome sob os alpendres de Lisboa; eram estrangeiros os artífices, os barbeiros, os sapateiros; muitos mil órfãos e viúvas depereciam na ociosidade; e o fidalgote que se exibia na rua, com mula ajaezada de oiro e muitos lacaios agaloados, recorria ao jejum portas a dentro. ${ }^{3}$

Desse modo, a personagem criada pelo autor d'Os Lusíadas pode apontar para duas vertentes: ela é tanto a voz da sabedoria, que é capaz de prever as conseqüências de um processo em plena ocorrência, mas que os mais ufanistas insistem em não enxergar, como também pode ser a voz que representa a classe conservadora - aquela dedicada à economia agrária e pastoril, principalmente que se sente prejudicada pelo despovoamento causado pela busca das riquezas orientais, procurando defender a manutenção dos habitantes no país, não só para o desenvolvimento das atividades agrárias, mas também para dar continuidade às lutas contra os árabes que estão mais próximos - os de África.

Devido, portanto, ao caráter ambígüo e contraditório que marca este momento de Os Lusíadas, o episódio do Velho do Restelo pode ser reapresentado em novos contextos literários, de forma a proporcionar leituras que questionem o maior feito da nação portuguesa. Isto é o que ocorre em dois romances de nossa época, Boca do Inferno, de Ana Miranda, e Memorial do Convento, de José Saramago.

Antes de mais nada, citamos aqui os trechos dos dois romances que remetem àquele episódio.

${ }^{3}$ SÉRGIO, 1972. p.96. 
"Para isso foi que abrimos os mares nunca dantes navegados?", disse Vieira cravando seus olhos redondos no rosto do irmão. "Para isso descobrimos as regiões e os climas não conhecidos? Para isso contrastamos os ventos e as tempestades com tanto arrojo, que apenas há baixio no oceano que não esteja infamado com miserabilíssimos naufrágios de portugueses? E depois de tantos perigos, depois de tantas desgraças, depois de tantas e tão lastimosas mortes, ou nas praias desertas sem sepultura, ou sepultados nas entranhas dos alarves, das feras, dos peixes, que as terras que assim ganhamos as hajamos de ver assim?"4

Corriam as mulheres, choravam, e as crianças acresciam o alarido, era como se andassem os corregedores a prender para a tropa ou para a Índia. Reunidos na praça de Celorico da Beira, ou de Tomar, ou em Leiria, em Vila Pouca ou Vila Muita na aldeia sem mais nome que saberem-no os moradores de lá, nas terras da raia ou da borda do mar, ao redor dos pelourinhos, no adro das igrejas, em Santarém e Beja, em faro e Portimão, em Portalegre e Setúbal, em Évora e Montemor, Bragança e Vila Real, em Miranda, Chaves e Amarante, em Vianas e Póvoas, em todos os lugares aonde pôde chegar a justiça de sua majestade, os homens, atados como reses, folgados apenas quanto bastasse para não se atropelarem, viam as mulheres e os filhos implorando o corregedor, procurando subornar os quadrilheiros com alguns ovos, uma galinha, míseros expedientes que de nada serviam, pois a moeda com que el-rei de Portugal cobra os seus tributos é o ouro, é a esmeralda, é o diamante, é a pimenta e a canela, é o marfim e o tabaco, é o açúcar e a sucupira, lágrimas não correm na alfândega. E se para isso tiveram tempo, quadrilheiros houve que se gozaram das mulheres dos presos, que a tanto se sujeitaram as pobres para não perder os seus maridos, porém desesperadas os viam depois partir, enquanto os aproveitadores se riam delas, Maldito sejas até à quinta geração, de lepra se te cubra o corpo todo, puta vejas a tua mãe, puta a tua mulher, puta a tua filha, empalado sejas do cu até a boca, maldito, maldito, maldito. Já vai andando a récua dos homens de Arganil, acompanham-nos até fora da vila as infelizes, que vão clamando, qual em cabelo, Ó doce e amado esposo, e outra protestando, Ó filho, a quem eu tinha só

${ }^{4}$ MIRANDA, 1997. p.52. 
para refrigério e doce amparo desta cansada já velhice minha, não se acabavam as lamentações, tanto que os montes de mais perto respondiam, quase movidos de alta piedade, enfim já os levados se afastam, vão sumir-se na volta do caminho, rasos de lágrimas os olhos, em bagadas caindo aos mais sensíveis, e então uma grande voz se levanta, é um labrego de tanta idade já que o não quiseram, e grita subido a um valado que é púlpito de rústicos, Ó glória de mandar, ó vã cobiça, ó rei infame, ó pátria sem justiça, e tendo assim clamado, veio dar-lhe o quadrilheiro uma cacetada na cabeça que ali mesmo o deixou por morto. ${ }^{5}$

São estas, na verdade, duas apropriações bem diferentes do episódio do Velho do Restelo, mas que refletem o contexto de corrupção - apresentado em Boca do Inferno - e autoritarismo e repressão - recriado nos dois romances. Desse modo, é fundamental a contextualização das duas passagens.

Boca do Inferno (1989) narra os feitos do poeta Gregório de Matos, o Boca do Inferno, durante sua estada na Bahia no final do século XVII - mais exatamente nos anos de 1683 e 1684. Este é um momento em que estão em luta duas facções: a do governador Antonio de Souza e a da família do Padre Vieira - os Ravasco -, à qual se liga Gregório de Matos. O romance centra-se, portanto, na tentativa da facção dos Ravasco de destituir o governador, alcunhado Braço de Prata, responsável por uma administração corrupta em que os inimigos são perseguidos, alguns levados mesmo à morte. A fala de Vieira aqui citada constitui-se então num questionamento a este sistema autoritário e corrupto que se instaurou na colônia, ou nas colônias, já que "as terras que assim ganhamos", mencionadas por Vieira, podem dizer respeito ao império colonial como um todo.

Memorial do Convento (1982) narra dois grandes feitos: de um lado a construção do Convento de Mafra e de outro a construção de um artefato voador, denominado passarola. Estes fatos dão-se no reinado de D. João V, ou seja, início do século XVIII, um período bastante próximo daquele retratado em Boca do Inferno. A

${ }^{5}$ SARAMAGO, 1994. p.293. 
passagem aqui citada refere-se ao momento em que D. João V, temendo não viver o suficiente para sagrar ele mesmo o Convento de Mafra, obra grandiosa que mandara construir em honra de uma promessa feita pelo nascimento do príncipe herdeiro (nasce-lhe uma menina, contudo) manda arrebanhar mão-de-obra compulsória entre os trabalhadores do reino. O trecho acima mostra, portanto, a violência empreendida pelos oficiais de el-rei no intuito de fazer cumprir a vontade real, mesmo a custo da humilhação, dos maus tratos e até mesmo da morte de pessoas do povo.

Está claro então que ambos os romances remetem a um contexto de opressão, violência e miséria no qual o poder constituído não hesita em dispor da vida de seres humanos para atingir objetivos vãos - em Memorial do Convento - ou sórdidos em Boca do Inferno. Este contexto relaciona-se com a fala do Velho do Restelo, cujas imprecações prevêem um futuro de miséria e violência para Portugal. O país irá se despovoar com as navegações, faltando assim mãos para o trabalho agrário, e os inimigos - os árabes que se encontram nas proximidades do reino - ganharão força, pois não serão propriamente combatidos, o que poderá levar a invasões e perdas territoriais posteriores.

Em Boca do Inferno, as palavras de Vieira ecoam o discurso da personagem de Camões. No romance, o jesuíta é um homem idoso (tem em torno de 75 anos), respeitável pela obra religiosa e política que realizou ao longo da vida tanto em Portugal como no Brasil, recriando a imagem de um "velho de aspeito venerando" como o do poema épico de Camões. No momento da fala citada, Vieira é um homem desiludido com a política colonial. É a época do reinado de D. Pedro II, quando Vieira já havia caído das graças da realeza e tinha passado pelo processo de Inquisição. Para o rei e para os homens ligados à administração do reino, o padre jesuíta era apenas um velho, cujas palavras não deveriam mais ser levadas a sério, como haviam sido durante o reinado de D. João IV.

As perguntas que Vieira dirige ao irmão revisam o processo das navegações e do descobrimento das novas terras, enfatizando as dificuldades enfrentadas pelos portugueses para vencer as longas 
distâncias e os mares revoltos, cheios de perigos. Apesar do teor crítico, a fala de Vieira não minimiza de maneira alguma o empreendimento náutico português. Muito pelo contrário, ao se referir aos perigos superados para chegar às regiões desconhecidas, que nos séculos anteriores haviam produzido um imaginário de deleites e de monstruosidades, Vieira valoriza a empresa portuguesa, mostrando a grandiosidade do evento. A intenção de Vieira não é, portanto, desqualificar a grande obra portuguesa, como o faz o Velho do Restelo por achá-la produto somente da "glória de mandar" e da "vã cobiça". Sua crítica recai sobre o modo como vem sendo administrado o império colonial conquistado com as navegações.

No contexto do romance, o governo autoritário e corrupto do Braço de Prata impede o desenvolvimento da colônia pela má utilização das verbas públicas, que são desviadas para o enriquecimento tanto do governador como dos seus aliados políticos, situação esta que nos é bastante conhecida. Veja-se a atualidade dessa fala do Vereador Luiz Bonicho, personagem esta que era responsável pela realização dos negócios escusos do Braço de Prata, mas que depois se revolta contra ele:

"Venais? Está bem, somos venais. Mas quem não o é nesta cidade? Acham que aqui é possível administrar justiça igual para todos? Só um bastardo de padre acredita nessa hipocrisia. Não, não é possível. Então o que fazemos nós, os vereadores? A segunda melhor opção: se não podemos beneficiar a todos então vamos beneficiar a alguns. A quem? Ora, aos senhores da cana, à aristocracia proprietária dos escravos. A quem mais? Ao alcaide. Aos desembargadores. Ao governador. A quem mais? A nós mesmos. O que há de venal nisso?’6

É esta postura que Vieira critica com sua fala. Como homem velho, cujo saber não é "só de experiências feito", mas sim de um profundo senso crítico, adquirido através das leituras, conjugado às experiências políticas e religiosas tanto coloniais como européias, o padre jesuíta consegue expor a incapacidade do sistema monár-

${ }^{6}$ MIRANDA, 1997. p.42. 
quico absolutista português de controlar o vasto império conquistado com as navegações.

Como a fala do Velho do Restelo, a de Vieira também é ambígüa. Por um lado, ela representa a consciência crítica de um homem ligado aos meandros da política de seu tempo e que é capaz de perceber mais claramente os problemas da administração colonial, que podem conduzir a metrópole a uma profunda decadência, como já há algum tempo é sentida. Por outro, esta também é a voz de um homem ressentido, que perdeu a condição privilegiada que possuía no reinado de D. João IV, quando tinha ascendência sobre o rei, conseguindo inclusive interferir nos destinos da nação. Este ressentimento se traduz em crítica ao sistema vigente, crítica esta que questiona a validade do maior feito português pelas conseqüências a que assiste de tal feito.

Enquanto na passagem extraída do romance de Ana Miranda a relação com o discurso do Velho do Restelo não se dá de maneira explícita, chegando-se a ele através do tom e do objeto do questionamento, além do fato de a fala provir de uma personagem que nos remete à personagem camoniana, na passagem extraída de Memorial do Convento, a relação com o episódio d'Os Lusíadas é muito mais aparente. Na verdade, o trecho que citamos constituise numa paródia àquelas estrofes.

Na primeira citação, a que reproduz as palavras de Vieira, só o discurso do Velho ecoa em nossas mentes. Já na citação seguinte, o autor faz uma releitura de quase todo o episódio, desde o momento melancólico que precede a partida - estrofes 89 a 93 - até a descrição do Velho e o início de sua fala - estrofes 94 e 95.

Saramago reelabora ideologicamente o episódio, procurando enfatizar os desmandos de um rei que não hesita em levar o povo ao sofrimento e à miséria para satisfazer sua vaidade.

N’Os Lusíadas, Camões dá voz às mulheres para que elas reproduzam o lado triste da aventura marítima - o fato de mães, esposas, irmãs perderem tanto a companhia de seus homens, como também perderem o amparo material que eles lhes proporcionam. 
No trecho citado de Memorial do Convento, o autor também reproduz o desespero das mulheres, só que, enquanto n' Os Lusíadas as mulheres choram e clamam utilizando-se do discurso do amor amor filial, amor conjugal, amor fraterno - para tentar dissuadir seus filhos, irmãos e companheiros da partida, no romance de Saramago, as mulheres deixam o âmbito do sublime, do Amor com "a" maiúsculo, e vão para o âmbito da degradação. Primeiro elas tentam subornar os quadrilheiros com o pouco que têm para a subsistência - ovos, galinhas. Não vendo resultado, oferecem o corpo, como prostitutas, tentando evitar que os homens sejam levados, pois a violência da ação dos oficiais do rei leva-as a desconfiar que eles jamais voltarão.

Ao perceber que seus esforços para salvar os homens foram vãos, elas passam a dirigir ofensas em baixo calão aos quadrilheiros. Nesse momento, há todo um jogo de prosaico-sublime, baixoelevado, pois logo após as ofensas, que estão no nível do baixo, ouvem-se delas as mesmas palavras pronunciadas pelas mulheres n'Os Lusiadas, palavras que estão no nível do sublime: "Ó doce e amado esposo (...) Ó filho, a quem eu tinha só para refrigério e doce amparo desta cansada já velhice minha”, modo este de falar que se opõe inteiramente ao que haviam dito antes. Assim, as mesmas mulheres que são capazes de ir ao nível mais baixo em defesa dos maridos humilhados, são capazes de produzir o discurso mais elevado para traduzir seus sentimentos pelos homens amados e o sofrimento diante daquela situação.

A elevação dura até o aparecimento da figura do velho propriamente dita. Aí então a paródia se revela em toda a sua dimensão. O "velho de aspeito venerando" de Camões torna-se "um labrego de tanta idade" - uma degradação na representação do velho. Como no episódio d'Os Lusíadas, a voz do velho é potente sobressaindo-se entre as demais, e as primeiras palavras que ele profere são as mesmas do Velho do Restelo: "Ó glória de mandar, ó vã cobiça”, mas a continuação do discurso é bem diferente da do seu predecessor: "ó rei infame, ó pátria sem justiça”, uma referência 
ao momento de opressão e injustiça que o romance recria. Estas palavras e a conclusão do episódio representam uma completa subversão do episódio camoniano, pois é o grotesco que se instaura quando da cacetada do quadrilheiro que deixa o velho morto sem terminar o discurso.

Esta passagem é bastante representativa do processo de desconstrução dos mitos nacionais realizado ao longo do romance. Ao tratar de um momento da história portuguesa no qual se procurou produzir uma obra de vulto como o Convento de Mafra, o autor vai revelando fatos que cercaram esta construção que não são mencionados nos textos históricos. Saramago faz, portanto, uma releitura da história portuguesa do ponto de vista das classes marginalizadas, trazendo à luz a opressão e a violência que são marcas constantes dos grandes feitos históricos, o que nos faz lembrar W. Benjamin quando diz que "Nunca houve um monumento da cultura que não fosse também um monumento da barbárie".

O Convento de Mafra é um monumento que deveria ser cercado pelo ideal de justiça, caridade e fraternidade, já que busca a aproximação do homem com Deus, numa época em que muitas das realizações humanas estavam voltadas para o objetivo de ascensão aos céus. Contudo, ele se torna a causa das misérias de Portugal, pois boa parte das riquezas que afluem ao reino vindas das colônias, assim como toda a força de trabalho do país, são canalizadas para sua construção. Em Memorial do Convento, o autor mostra como esta obra se transforma num monumento da barbárie ao retratar as condições miseráveis de vida do grosso da população, além das mortes e mutilações que a construção vai provocando. No romance, a pobreza do povo é fruto da ganância e impiedade dos governantes, apresentadas no trecho citado quando é dito: "a moeda com que el-rei de Portugal cobra os seus tributos é o ouro, é a esmeralda, é o diamante, é a pimenta e a canela, é o marfim e o tabaco, é o açúcar e a sucupira, lágrimas não correm na alfândega”.

7 BENJAMIN, 1985. p.225. 
Todas estas riquezas não servem para tornar digna a vida das massas - elas são apenas um meio de satisfazer a vaidade de D. João V.

Como na passagem citada de Boca do Inferno, a parte que se refere mais diretamente ao Velho do Restelo em Memorial do Convento também é ambígüa. O homem que fala pode ter levantado a voz tanto pelo fato de ter sido desprezado pelos quadrilheiros, um dado irônico num romance marcado pela ironia, como pelo fato de ser aquele que detém a sabedoria e por isso pode apontar as mazelas do reino. Desse modo, este velho está bem próximo de Vieira. Contudo, enquanto Vieira é um homem conhecido e respeitável, o velho do romance de Saramago não passa de um anônimo, vulgar e grosseiro - um labrego.

Vê-se então que as ambigüidades e contradições, não só da fala da personagem, mas de todo o episódio do Velho do Restelo permitem que dele sejam feitas releituras ideológicas, colocando em foco os problemas advindos com a descoberta das novas terras. Nas colônias, a incompetência da administração real faz com que as riquezas se percam nas mãos de funcionários corruptos (Boca do Inferno). Em Portugal, o mal uso feito das riquezas coloniais torna o país um espaço de miséria, opressão e violência (Memorial do Convento). Portanto, a forma como este momento da epopéia camoniana foi apropriado mostra que os dois autores viram nele, além do discurso questionador, a crítica a um sistema que conduz tanto Brasil como Portugal à decadência, dando margem à reconstrução ideológica que realizam nas duas obras. 


\section{Referências Bibliográficas}

BENJAMIN, Walter. Magia, e técnica, arte e politica. Trad. de Sérgio Paulo Rouanet. São Paulo: Brasiliense, 1985 (Obras Escolhidas - v.1).

CAMÕES, Luís de. Os Lusíadas. 9. ed. São Paulo: Cultrix, 1995.

D’Onofrio, Salvatore. "O Velho do Restelo e a Consciência Crítica de Camões". Revista de História, São Paulo, n.81, p.75-89, 1970.

MIRANDA, Ana. Boca do Inferno. 2.ed. São Paulo: Companhia das Letras, 1997.

SARAMAGO, José. Memorial do Convento. 11.ed. Rio de Janeiro: Bertrand Brasil, 1994.

SÉRGIO, António. Breve Interpretação da História de Portugal. 2.ed. Lisboa: Livraria Sá da Costa, 1972.

\section{Resumo}

Neste texto, tratamos de duas apropriações do episódio do Velho do Restelo em romances de nossa época - Boca do Inferno (1989), de Ana Miranda, e Memorial do Convento (1982), de José Saramago. Procuramos então mostrar como a ambigüidade e a contradição que cercam o episódio dão margem a que os versos da epopéia camoniana apareçam em contextos marcados pela corrupção, autoritarismo e violência, levando a uma revisão do grande feito português dos descobrimentos pelas conseqüências que ele provocou.

\section{Summary}

In this text, we deal with two appropriations of the episode of the Velho do Restelo in two novels of our time - Boca do Inferno (1989), by Ana Miranda, and Memorial do Convento (1982), by José Saramago. We try to show then how the ambiguity and the contradiction that pervade the episode make it possible that the Camonian epic verses appear in contexts of corruption, authoritarianism and violence, leading to a review of the great Portuguese new land discovery accomplishment through its consequences. 